\title{
SOCIAL AND TECHNOLOGICAL CONCERNS ASSOCIATED WITH THE USAGE OF UBIQUITOUS COMPUTING TECHNOLOGIES
}

\author{
Carsten Röcker, RWTH Aachen University, roecker@humtec.rwth-aachen.de
}

\begin{abstract}
This paper identifies social and technological concerns, which are likely to emerge through the integration of Ubiquitous Computing technologies in future work environments. The concerns presented in this paper were collected by reviewing relevant literature from different research domains and are clustered into two groups. The first group of concerns concentrates on the violation of individual user privacy and the consequences, which arise from these privacy breaches. The second group addresses environmental and societal transformation processes caused by a large-scale penetration of future information and communication technologies into everyday life.
\end{abstract}

Keywords: Ubiquitous and Pervasive Computing, Ambient Intelligence, Human Factors, Technology Acceptance, User Requirements.

\section{INTRODUCTION}

The pervasive integration of Ubiquitous Computing technologies into future work environments will enable workgroups to communicate and collaborate in new and more efficient ways. The theoretical advantages range from increased work productivity through time-saving operations to higher work satisfaction through attentive and reactive environments. Especially in the context of intellectual teamwork, the usage of Ubiquitous Computing technologies can lead to considerable benefits in a variety of areas and on different organizational levels (see [50] for more details). The changes the envisioned technologies will bring are likely to go far beyond those of technological developments in the past. The magnitude of potential implications is often attributed to the inherent characteristics of Ubiquitous Computing. So far, technological developments never intended to change the world or society, but rather did so as a side effect [33]. In contrast, the vision of Ubiquitous Computing explicitly aims at transforming the world (see [7] and [10]) by providing technology, that will accompany us throughout our whole lives, day in and day out [33]. In this context, Araya [4] even sees Ubiquitous Computing as the most explicit attempt to move computing technology beyond the confines of tool usage and towards a pervasive penetration of the everyday world.

Like the introduction of the personal computer some decades ago, ubiquitously available information technology will produce nothing fundamentally new, but by making everything faster and easier to do, it will transform what is apparently possible [56]. And these potential transformations are likely to be farreaching and manifold. For example, Bohn et al. [7, 10] anticipate, that the balance of political and economic power could shift, that personal borders could be violated by new surveillance and data retrieval technologies, and, most importantly, that there is a danger that users will lose confidence in their environment, which could fundamentally change their attitude towards the world that surrounds them. Adamowsky [2] even goes further and expects fundamental changes in the conception of time and space as well as in the relation between individuals and their environment.

From today's perspective, most authors believe, that the consequences of Ubiquitous Computing on everyday life are quite predictable, and in some cases even unavoidable. Nevertheless, it is important to note, that the nature of future computer applications is rather unclear. Especially in the work domain, only very limited knowledge exists about the impact of these technologies on business processes, and how these applications can create an added value for companies [23]. This 'vagueness of the vision' [2] is caused by a considerable divergence between the technical feasibility and the ability to use it in a beneficial way [8], or, as Thackara [53] expresses it more metaphorically, we are "brilliant on means, but pretty hopeless when it comes to ends". In literature, this situation is often referred to as the 'innovation dilemma' and one of the main differences to previous revolutionizing developments, like, for example, the printing press [24].

\section{RESEARCH GOAL AND APPROACH}

This paper aims to identify the prospective concerns associated with the usage of Ubiquitous Computing technologies in work environments by incorporating different types of information sources. Some of the expected problems are logical consequences of technological shortcomings, and therefore have long been identified on a theoretical basis. Relevant knowledge is acquired by reviewing state-of-the-art 
literature of different research domains, including computer science, engineering, management, economics, psychology, anthropology and social science. In addition, the different types of services and applications are analyzed from a technical as well as non-technical point of view in order to identify concerns, which are not yet addressed in literature.

\section{POTENTIAL CONCERNS OF FUTURE COMUPTER TECHNOLOGIES}

The analysis of existing literature revealed, that the majority of concerns can be clustered into two groups. The first group of concerns addresses the violation of individual user privacy and the consequences, which arise from these privacy breaches. The problems and concerns are usually directly related to the usage of Ubiquitous Computing technologies in general, or are caused by poorly implemented applications and inadequately engineered hardware. While these concerns are evoked by an individual application or singular incident, the concerns of the second group result from a large-scale penetration of Ubiquitous Computing technologies into everyday life. In this context, farreaching and long-term consequences are discussed, which might lead to a fundamental transformation of society as a whole.

Before the potential concerns are illustrated, it is important to note, that the augmentation of everyday objects with sensing, computing and communication capabilities has no negative implications per se [32]. However, so far there is only limited knowledge about how these technologies will be used in office environments, and how they will influence future business processes [23]. Although a wide variety of usage scenarios was developed within the last years, there are only few concrete applications that were actually tested in everyday office situations. Hence, the concerns, which are raised in the various papers that have been reviewed, are mostly based on an extrapolation of the current technological trends. Even if this is done with great care and based on evolutional trends of the last decades, it is still possible, that some of the listed concerns will turn out to be unjustified or that additional problems will arise. Nevertheless, it is important to be aware of the potential changes that these new technologies could bring, both in a positive and negative way.

\section{Violation of Individual Privacy}

Loss of Privacy. Since the introduction of personal computers in the early 1980 s, there is an ongoing debate about the potential fears of using electronic data processing technologies to monitor employees at the work place (see, e.g., [35]). Surveys conducted during the last 30 years showed, that the belief about the loss of personal privacy is associated with the quantity of personal data collected, and that the fear of privacy infringements constantly increases with the integration of computers into everyday life [49]. With the diffusion of Ubiquitous Computing technologies into office environments, the chances for both, intended and unintended privacy breaches will dramatically increase in the future. The reason for this is a new quality of data collection, that varies considerably from the capabilities of current computational systems. From a user's point of view, the two most important differences of Ubiquitous Computing technologies are the always-on nature of the devices and the invisibility of the technology.

With current systems, the duration of data collection and potential surveillance is clearly limited to the time a person uses the system. But when interacting with smart objects and environments, this clear distinction between 'online' and 'offline' will often no longer be possible [36, 37]. And while current applications usually only collect singular observations, future systems will use sensors to continuously and unobtrusively capture detailed realtime data, like the current location of users or their activity. As this is mostly done using automated capturing mechanisms, users have very little control over the data that are generated, which is especially dangerous, as most office systems are designed to be continuously active and are therefore highly sensitive to privacy issues [22].

The vision of Ubiquitous Computing implies, that computers are integrated into the physical environment, and hence are effectively invisible to the user, rather than being distinct objects on the desktop. Due to their appearance, smart office devices might not be perceived as computers anymore, although they could be of considerable size. Embedding computers and sensors into the users' surrounding, and thereby making them available throughout the whole working environment, enables people to move around and interact with computers more naturally than they currently do. But at the same time this also means, that sensory borders disappear and common principles like 'if I can see you, you can see me' no longer hold [30], which is one of the reasons, why the scanning and storing of data can go largely unnoticed by the person concerned [55].

Misuse of Personal Data. In addition, various aspects related to the protection of personal data are going to change. Especially the abilities to capture, store and search information will be significantly improved by new technologies and more powerful 
algorithms, which makes the protection of personal privacy even more important.

The continuous collection of personal data is one of the core requirements of most Ubiquitous Computing applications. In future office environments, smart objects and environments will collect a large amount of partially sensible data in order to provide contextadapted services. Hence, Ubiquitous Computing technology will significantly increase the quantitative as well as qualitative possibilities of monitoring users, and also extend them to spheres, which are currently out of the reach using existing hardware [11]. Lucky [34] goes even further and envisions a future of all-knowing and all-reporting objects, and expects the old sayings that 'the walls have ears' and 'if these walls could talk' to become the disturbing reality soon. But even it this vision is a bit too pessimistic, embedded sensors and location systems will definitely lead to the disappearance of most natural and spatial borders, and thereby also eliminate economic factors, which made privacy intrusions costly in the past [54].

Another characteristic, that sets Ubiquitous Computing systems apart from current applications is the a priori nature of the data collection. In existing Ubiquitous Computing applications, 'smart' system reactions are usually based on context information, which, in turn, is gained by combing various lowlevel sensor data and relating them to similar events in the past. In contrast to methods used in the area of Artificial Intelligence, this approach requires to continuously collect and store data, as only a retrospective data analysis might reveal certain relations, which characterize a specific situation [33]. As the prices for memory are constantly decreasing, it is very likely that the majority of information, which is currently available, will never be completely deleted and thereby 'forgotten' [39]. And with wireless communication infrastructures becoming ubiquitously available, these data can be accessed anytime and anyplace. Hence, the limits of universal information access will be less of a technological nature than economic or even legal one [36].

Even if some of the information is not harmful itself, the combination of several potentially harmless observations might lead to unexpected insights and, in consequence to severe violations of personal privacy [41]. Once context information is extracted from the raw sensor data, the information is usually stored in personal profiles, which get more detailed over time. Although data mining and information retrieval are research disciplines in themselves, the developed algorithms will be a basic building block of future Ubiquitous Computing systems, as most of the envisioned applications require precisely these capabilities [8]. Therefore, a variety of authors (e.g., Culnan and Bies [13], Perrin [47] or Spinello [51]) see the most important threat of Ubiquitous Computing not in the ability to capture various types of data, but in the ability to permanently save and link this information. One solution to circumvent such problems would be the anonymization or pseudonymization of all personal information. Nevertheless, with anonymous profiles getting more and more detailed and correlation algorithms becoming more sophisticated, the chances that anonymous profiles could be retrospectively linked to individuals are quite high [43].

While Fano and Gershman [21] expect the social acceptance for capturing and storing personal information to grow, as people get used to Ubiquitous Computing technologies, other authors anticipate enormous social problems. For example Mattern [40, 42] fears, that the balance of freedom and security could be disequilibrated, as the qualitative and quantitative possibilities of monitoring are extended to areas, where continuous and unobtrusive surveillance was not possible in the past. Similar concerns are raised by privacy activist groups, like, e.g., CASPIAN, who claim the risk, which RFID technology poses to humanity to be on par with nuclear weapons (see [17]). But even if the consequences of Ubiquitous Computing are not yet completely predictable, it is quite obvious, that current data protection laws are by no means prepared for the development of omnipresent data capturing and processing [55]. And also existing security mechanisms (like firewalls, certificates or cryptographic keys), which usually require a static structure and a central authority, are neither suitable nor scalable enough to meet the requirements of a smart world [33].

\section{Transformation of Environment and Society}

While most previous concerns were raised within the field of computer science and are mostly directly caused by the technology itself, current research in the area of social science focuses on the negative consequences and side effects resulting from the usage of these technologies. The main topics discussed in this area include an acceleration of life, loss of control caused by disloyal smart objects, and an increased feeling of powerlessness as a result of these changes [37].

Loss of Control. Already today, more and more everyday objects, like cars, air conditions or telephones are equipped with modern computer technology. Nevertheless, we are still able to decide for ourselves, whether we want to use such smart devices or not. Hence, there is always the possibility to escape such smart environments by choosing manual control for the central heating, or decide not 
to carry a mobile phone, if we dislike the constant accessibility [7]. But in a world full of smart objects, it might not be possible to escape from this sort of technologically induced dependency, which leads to a feeling of having 'lost control' [32]. In HCI research, the term 'loss of control' is usually defined as a combination of helplessness, powerlessness and a low expectation of self-efficiency, which users experience, if they do not have control over a certain process or functionality [12].

So, if the behavior of autonomous objects is too complicated to understand, or if the devices do not function in the expected way, users might become mistrustful and finally see the objects in a negative light [55]. As such incidents repeat themselves, users are likely to loose trust in the environments as a whole and will inevitable change their general attitude towards the world surrounding them [37]. Hence, when designing Ubiquitous Computing applications, it is important to give users a feeling of control over their environment and a sense of the 'loyalty' of objects inhabiting the environment [9].

High Dependency on Technology. Relying on smart objects and autonomous agents to perform routine tasks will inevitable lead to a high dependency on these applications and the underlying technical infrastructure. Personal electronic assistants, for example, are often cited as one of the most promising application domain for Ubiquitous Computing technologies. Like with human assistants, the benefits, in terms of time and labor savings, increase with the amount of autonomy users grant their electronic helpers. But this electronic assistance comes at the price of a high technological dependency, where system failures can easily lead to total helplessness [42]. The technological dependency is even higher for central infrastructure components, like networks, which connect several smart services. The consequences of large-scale breakdowns are likely to exceed the disastrous effects of power-shortages, experienced in multiple industrial countries within the last years. The reasons for system malfunctions are manifold, ranging from design failures and material defects to system overload or even sabotage [40]. Besides this, such a high dependability on technology is particularly questionable, as the general attitude towards technology considerably changed over the last decades. While people during the 1960s still regarded technology as a blessing, this positive attitude considerably changed in the 1980s, when more and more people started to regard technical innovation with skepticisms [57].

But dependability is not guaranteed by technological reliability alone. Especially complex and highly dynamic systems, like Ubiquitous Computing applications, must also remain manageable and controllable, and users must be able to anticipate the reactions of the system [7]. If users are not capable of predicting the behavior of the system, they have no means to verify whether it works correctly. Traditional electronic devices, such as telephones or televisions, are relatively easy to use and enable even technically untrained users to detect malfunctions easily [8]. But with computers being embedded into the physical environment, and systems being expected to function without users noticing their presence [10], it becomes more and more complicated to verify proper system behavior and detect potential malfunctions $[12,19]$.

Interruption of Work Processes. Another problem often associated with the introduction of new technologies into workspaces are increased interruptions, caused by the usage of these technologies. Especially in office environments, where work usually requires a high level of concentration [52], the need for quiet and uninterrupted work is a key issue in workplace productivity [31]. The introduction of new technologies in the past showed, that sources of interruptions dramatically increased [16]. Several studies revealed that especially new communication technologies, like e-mail and instant messaging applications, are today's main source of interruptions in office environments. For example, Jackson [28] found that, on average, users took 64 seconds to "recover the mental thread" of what they were doing before in order to be able to resume previous tasks. Those interruptions do not only cause users to complete their tasks slower (see, e.g., [5], [6], [20], [14] or [15]), many interruptions (41\%) do also result in the discontinuing of the interrupted task beyond the duration of the interruption itself [45]. Studying interruptions in work environments, Hudson et al. [26] observed, that some participants considered interruptions, caused by electronic media so distracting, that they physically moved, either within the work space or to some place outside the office. Especially for continuously operating systems, like Ubiquitous Computing applications, resource demands are usually high, and the opportunities for unwanted interruptions go up dramatically [27].

Changes in Organization of Work. The use of technology in social systems is always accompanied by a variety of changes, some are intended or at least expected, others are not [44]. In this context, Ubiquitous Computing will not only provide new functionalities and services, it will also influence the way people act and interact with each other. According to Jessup and Robey [29], this requires to fundamentally reassess the meaning of human action 
and interaction, as social actions are likely to occur in entirely new ways, and completely new social actions might appear.

Effects on Employment. While some authors, like, e.g., Mattern [38, 40] expect Ubiquitous Computing to give rise to a whole new industry, similar to the energy or telecommunication industry, most others fear severe consequences for employment due to increased rationalization. Which effect will outweigh the other is not yet clear. Nevertheless, the usage of Ubiquitous Computing technology will open up a variety of new possibilities to rationalize business processes in different areas, and especially unskilled workers are likely to be substituted by intelligent machines. The same could happen to secretaries, personal assistants or bookkeepers in the office domain.

Effects on Environment and Health. Finally, Ubiquitous Computing will not only change the nature of man-made objects, it is also likely to have an influence on nature itself. One of the main risks, associated with the large-scale usage of wirelessly communicating, smart objects is electromagnetic radiation (see, e.g., Duce [18] or Thiesse [54]). Even if it is not yet fully understood whether and to what extent electromagnetic radiation affects physical health [7], its potential environmental effects could have a permanent impact on the lives of future generations [25]. Especially personal artifacts and wearable computers bear the potential to increase the electromagnetic exposition, as the distance between the source of radiation and the body is known to have a strong influence on its intensity [55]. But not only electromagnetic radiation will increase. The integration of Ubiquitous Computing technologies into everyday objects will also significantly increase raw material as well as energy consumption, and will raise new question for disposal and lifecycle management [8].

\section{CONCLUSION}

The changes illustrated in this paper will not happen over night, instead, it is expected that they will materialize in a slow and continuous process [12]. But it is especially the graduality of the transformation process that many people worry about. As these small changes accumulate over time, they can lead to a dramatically new world. Hence, Mattern [37] fears, that with enough time, almost any new technology could be introduced, and whatever reservations might exist in the beginning, it is likely that the technology will not be rejected for long. In a similar fashion, the general attitude is likely to change, as people tend to forget quickly what things used to be like [46]. In this context, Pearson [46] reminds of analog incidents in the past, which lead to a complete inversion of morality within just two decades, and which made things, that were once socially unacceptable, highly fashionable. Therefore, it is important to be aware, that the designs, that dominate early in the growth of a technology, can have disproportionate power over the way the technology will affect social life [48]. So, if the potential concerns identified in this paper are not counteracted in an early stage of the technical development process, they are likely to influence technical as well as social standards of future applications for a long time.

\section{REFERENCES}

1. Abowd, G. D., Mynatt, E. D., Rodden, T. (2002). The Human Experience. In: IEEE Pervasive Computing, Vol. 1, No. 1, pp. 48 - 57.

2. Adamowsky, N. (2000). Kulturelle Relevanz. Ladenburger Diskurs 'Ubiquitous Computing', February 2000.

3. Agarwal, R., Prasad, J. (1999). Are Individual Differences Germane to the Acceptance of New Information Technologies? In: Decision Sciences, Vol. 30, No. 2, pp. 361 - 391.

4. Araya, A. (1995). Questioning Ubiquitous Computing. In: Proceedings of the 23rd Annual Conference on Computer Science, ACM Press, pp. $230-237$.

5. Bailey B. P., Konstan J. A., Carlis J. V. (2000). Measuring the Effects of Interruptions on Task Performance in the User Interface. In: Proceedings of the IEEE Conference on Systems, Man, and Cybernetics (SMC'00), pp. $757-762$.

6. Bailey, B. P., Konstan, J. A., Carlis, J. V. (2001). The Effects of Interruptions on Task Performance, Annoyance, and Anxiety in the User Interface. In: Proceedings of the Conference on Human-Computer Interaction (INTERACT'01), pp. 593 - 601.

7. Bohn, J., Coroama, V., Langheinrich, M., Mattern, F., Rohs, M. (2005). Social, Economic, and Ethical Implications of Ubiquitous Computing and Ubiquitous Computing. In: W. Weber, J. Rabaey, E. Aarts (Eds.): Ubiquitous Computing. Springer-Verlag, Heidelberg, pp. 5 29.

8. Bohn, J., Coroama, V., Langheinrich, M., Mattern, F., Rohs, M. (2003). Disappearing Computers Everywhere - Living in a World of Smart Everyday Objects. Paper presented at the Conference on New Media, Technology and Everyday Life in Europe, London, UK, April 2003. 
9. Bohn, J., Coroama, V., Langheinrich, M., Mattern, F., Rohs, M. (2003). Allgegenwart und Verschwinden des Computers - Leben in einer Welt smarter Alltagsdinge. In: R. Grötker (Ed.): Privat! Kontrollierte Freiheit in einer vernetzten Welt. Heise-Verlag, pp. $195-245$.

10. Bohn, J., Coroama, V., Langheinrich, M., Mattern, F., Rohs, M. (2004). Living in a World of Smart Everyday Objects - Social, Economic, and Ethical Implications. In: Journal of Human and Ecological Risk Assessment, Vol. 10, No. 5, pp. $763-786$.

11. Cas, J. (2002). Privacy in Ubiquitous Computing Environments? Paper presented at the 13th ITSEurope Regional Conference, Madrid, Spain, September 8-10, 2002

12. Coroama, V., Hähner, J., Handy, M., RudolphKuhn, P., Magerkurth, C., Müller, J., Strasser, M., Zimmer, T. (2003). Leben in einer smarten Umgebung: Ubiquitous-Computing-Szenarien und-Auswirkungen. Technical Report No. 431, ETH Zurich, December 2003.

13. Culnan, M. J., Bies, R. J. (2003). Consumer Privacy: Balancing Economic and Justice Considerations. In: Journal of Social Issues, Vol. 59, No. 2, pp. $323-342$.

14. Cutrell, E. B., Czerwinski, M., Horvitz, E. (2000). Effects of Instant Messaging Interruptions on Computing Tasks. In: Extended Abstracts of the ACM Conference on Human Factors in Computing Systems (CHI'00), pp. 99 $-100$.

15. Cutrell, E., Czerwinski, M., Horvitz, E. (2001). Notification, Disruption, and Memory: Effects of Messaging Interruptions on Memory and Performance. In: Proceedings of the Conference on Human-Computer Interaction (INTERACT'01), pp. $263-269$.

16. Dabbish L., Kraut R. (2004). Controlling Interruptions: Awareness Displays and Social Motivation for Coordination. In: Proceedings of the ACM Conference on Computer Supported Cooperative Work (CSCW'04), pp. 182 - 191.

17. Downes, L. (2003). Don't Fear New Bar Codes. USA Today, September 25, 2003.

18. Duce, H. (2003). Public Policy: Understanding Public Opinion. Executive Briefing, Auto-ID Centre, Institute for Manufacturing, University of Cambridge, Cambridge, UK.

19. Estrin, D., Culler, D., Pister, K., Sukhatme, G. (2002). Connecting the Physical World with Pervasive Networks. In: IEEE Pervasive Computing - Mobile and Ubiquitous Systems, Vol. 1, No. 1, pp. $59-69$.

20. Eyrolle H., Cellier J.-M. (2000). The Effects of Interruptions in Work Activity: Field and

Volume XI, No. 1, 2010
Laboratory Results. In: Applied Ergonomics, Vol. 31, No. 5, pp. $537-543$.

21. Fano, A, Gershman, A. (2002). The Future of Business Services in the Age of Ubiquitous Computing. In: Communications of the ACM, Vol. 45, No. 12, pp. $83-87$.

22. Farshchian, B. A. (2003). Presence Technologies for Informal Collaboration. In: G. Riva, F. Davide, W. A. IJsselsteijn (Eds.) Being There: Concepts, Effects and Measurement of User Presence in Synthetic Environments. Ios Press, Amsterdam, The Netherlands, pp. 209 - 222.

23. Fleisch, E., Tellkamp, C. (2003). The Challenge of Identifying Value-Creating Ubiquitous Computing Applications. Paper presented at the workshop on Ubiquitous Commerce, International Conference on Ubiquitous Computing (UbiComp'03), Seattle, USA.

24. Görisch, F., Hennig, F. (2006). Ambient Business - Ubiquitous Computing im wirtschaftlichen Kontext. Seminar on Novel Forms of Human Computer Interaction: Smart Artifacts and Ubiquitous Computing. Department of Computer Science, Technical University of Darmstadt.

25. Hilty, L., Behrendt, S., Binswanger, M., Bruinink, A., Erdmann, L., Fröhlich, J., Köhler, A., Kuster, N., Som, C., Würtenberger, F. (2003). Das Vorsorgeprinzip in der Informationsgesellschaft: Auswirkungen des Pervasive Computing auf Gesundheit und Umwelt. Studie des Zentrums für Technologiefolgen-Abschätzung TA-SWISS, TA 46/2003, August 2003.

26. Hudson, J. M., Christensen, J., Kellogg, W. A., Erickson, T. (2002). "I'd Be Overwhelmed, But It's Just One More Thing to Do": Availability and Interruption in Research Management. In: Proceedings of the ACM Conference on Human Factors in Computing Systems (CHI'02), pp. 97 $-104$.

27. Hudson, S. E., Smith, I. (1996). Techniques for Addressing Fundamental Privacy and Disruption Tradeoffs in Awareness Support Systems. In: Proceedings of the ACM Conference on Computer Supported Cooperative Work (CSCW'96), pp $248-257$.

28. Jackson, T. W., Dwason, R., Wilson, D. (2003). Understanding Email Interaction Increases Organizational Productivity. In: Communications of the ACM, Vol. 46, No. 8, pp. $80-84$.

29. Jessup, L. M., Robey, D. (2002). Issues and Challenges in Ubiquitous Computing: The Relevance of Social Issues in Ubiquitous Computing Environments. In: Communications of the ACM, Vol. 45, No. 12, pp. 88 - 91.

30. Lahlou, S., Langheinrich, M., Röcker, C. (2005). Privacy and Trust Issues with Invisible 
Computers. In: Communications of the ACM, Vol. 48, No. 3, ACM Press, New York, NY, USA, pp. $59-60$.

31. Lai, J., Yoshihama, S., Bridgman, T., Podlaseck, M., Chou, P., Wong, D. (2003). MyTeam: Availability Awareness through the Use of Sensor Data. In: Proceedings of the Conference on Human-Computer Interaction (INTERACT'03), pp. $503-510$.

32. Langheinrich, M., Coroama, V., Bohn, J., Mattern, F. (2005). Living in a Smart Environment - Implications for the Coming Ubiquitous Information Society. In: Telecommunications Review, Vol. 15, No. 1, pp. $132-143$.

33. Langheinrich, M., Mattern, F. (2002). Wenn der Computer verschwindet: Was Datenschutz und Sicherheit in einer Welt intelligenter Alltagsdinge bedeuten. In: digma - Zeitschrift für Datenrecht und Informationssicherheit, Vol. 2, No. 3, pp. $138-142$.

34. Lucky, R. (1999). Everything Will be Connected to Everything Else. In: Connections. IEEE Spectrum, March 1999, p. 19.

35. Lyon, D. (2001). Surveillance Society Monitoring Everyday Life. Open University Press, Buckingham, England.

36. Mattern, F. (2002). The Vision and Technical Foundations of Ubiquitous Computing. In: Upgrade, Vol. 2, No. 5, pp. $2-6$.

37. Mattern, F. (2003). Vom Verschwinden des Computers - Die Vision des Ubiquitous Computing. In: F. Mattern (Ed.): Total vernetzt. Springer-Verlag, Heidelberg, Germany, pp. 1 41.

38. Mattern, F. (2003). Ubiquitous Computing Eine Herausforderung für Datenschutz und Sicherheit. IT-Sicherheit im verteilten Chaos. SecuMedia-Verlag, Gau-Algesheim, Germany, pp. $519-531$.

39. Mattern, F. (2004). Allgegenwärtige Informationstechnik - Soziale Folgen und Konsequenzen für die Menschenrechte. In: P. Kirchschläger, T. Kirchschläger, A. Belliger, D. Krieger (Eds.): Menschenrechte und Terrorismus. Stämpfli Verlag, Bern, Switzerland, pp. $315-335$.

40. Mattern, F. (2004). Ubiquitous Computing: Schlaue Alltagsgegenstände - Die Vision von der Informatisierung des Alltags. In: Bulletin SEV/VSE, No. 19, pp. 9-13.

41. Mattern, F. (2005). Die technische Basis für das Internet der Dinge. In: E. Fleisch, F. Mattern (Eds.): Das Internet der Dinge - Ubiquitous Computing und RFID in der Praxis: Visionen, Technolgien,

Anwendungen,
Handlungsanleitungen. Springer-Verlag, Heidelberg, Germany, pp. 39 - 66.

42. Mattern, F. (2005). Leben und Lernen in einer von Informationstechnologie durch-drungenen Welt - Visionen und Erwartungen. In: M. Franzen (Ed.): Lernplattformen (Web-Based Training 2005). EMPA-Akademie, Dübendorf, Switzerland, pp. $39-61$.

43. Mattern, F., Langheinrich, M. (2002). Allgegenwärtigkeit des Computers Datenschutz in einer Welt intelligenter Alltagsdinge. In: G. Müller, M. Reichenbach (Eds.): Sicherheitskonzepte für das Internet, Springer-Verlag, Heidelberg, Germany, pp. 7 26.

44. Müller, G., Kreutzer, M., Strasser, M., Eymann, T., Hohl, A., Nopper, N., Sackmann, S., Coroama, V. (2003). Geduldige Technologie für ungeduldige Patienten: Führt Ubiquitous Computing zu mehr Selbstbestimmung? In: F. Mattern (Ed.): Total Vernetzt. Springer-Verlag, Heidelberg, Germany, pp. 159 - 186.

45. O'Conaill, B., Frohlich, D. (1995). Timespace in the Workplace: Dealing with Interruptions. In: Extended Abstracts of ACM Conference on Human Factors in Computing Systems (CHI'95), pp. $262-263$.

46. Pearson, I. (2001). What's next? In: $B T$ Technology Journal, Vol. 19, No. 4, pp. 98 106.

47. Perrin, S. (2005). RFID and Global Privacy Policy, In: S. Garfinkel, B. Rosenberg (Eds.): RFID. Addison-Wesley, Upper Saddle River, NJ, USA, pp. 15 - 36 .

48. Rheingold, H. (2003). Smart Mobs: The Next Social Revolution. Perseus Books, Jackson, TN, USA.

49. Robbin, A. (2001). The Loss of Personal Privacy and its Consequences for Social Research. In: Journal of Government Information, Vol. 28, No. 5, pp. $493-527$.

50. Röcker, C. (2009). Design Requirements for Future and Emerging Business Technologies: An Empirical Cross-Cultural Study Analyzing Technical and Psychological Requirements for Ubiquitous Computing Applications in Work Environments. Verlag Dr. Driesen, Taunusstein, Germany.

51. Spinello, R. A. (1998). Privacy Rights in the Information Economy. In: Business Ethics Quarterly, Vol. 8. No. 4, pp. 723 - 742.

52. Tanis, J., Duffy, F. (1999). A Vision of the New Workplace Revisited. In: Site Selection, 09/99, pp. $805-814$.

53. Thackara, J. (2001). The Design Challenge of Pervasive Computing. In: Interactions, Vol. 8, No. 3, pp. $46-52$. 
54. Thiesse, F (2006). Managing Risk Perceptions of RFID. Auto-ID Labs White Paper WP-BIZAPP031, Auto-ID Lab St.Gallen, Switzerland.

55. von Locquenghien, K. (2006). On the Potential Social Impact of RFID-Containing Everyday Objects Science. In: Technology \& Innovation Studies, Vol. 2, No 1, pp. 57 -78.

56. Weiser, M. (1991). The Computer for the Twenty-First Century. In: Scientific American, Vol. 265, No. 3, pp. $94-104$.

57. Wiedemann, P., Hennen, L. (1989). Schwierigkeiten bei der Kommunikation über technische Risiken. Arbeiten $\mathrm{zu}$ Risikokommunikation, Forschungszentrum Jülich, Germany. 